\title{
MARKETISATION OF TECHNICAL EDUCATION: A STYLISTIC EXPLORATION OF GHANAIAN TECHNICAL UNIVERSITY ANTHEMS
}

Peter Mwinwelle $\mathrm{e}^{1 \mathrm{i}}$, John Adukpo', Grace Asante-Anyimadu' ${ }^{3}$, Anita Avevor ${ }^{4}$

${ }^{1}$ Department of General Studies, Koforidua Technical University, Ghana

${ }^{2}$ Department of Languages, Dambai College of Education, Ghana

${ }^{3}$ Department of Languages, Methodist College of Education, Akim Oda, Ghana ${ }^{4}$ Department of Languages, Dambai College of Education, Ghana

\section{Abstract:}

Technical education is a major boost to national development because it helps in job creation. This makes technical universities important institutions. The upgrade of polytechnics to technical universities in Ghana has been an important milestone in the enhancement of technical and vocational education. Due to this upgrade, technical universities which were hitherto polytechnics had to compose new anthems to indicate and reflect their new status as universities. The present study focuses on how stylistically significant devices are used to construe the goals of technical and vocational education in anthems of Ghanaian technical universities. The study adopts the descriptive qualitative methodological approach which is theoretically framed by the linguistic and stylistic categories theory postulated by Leech and Short (2007). Anthems of six out of the ten technical universities in Ghana were homogenously sampled using the purposive sampling technique. The sampled anthems which served as data for the study were manually coded using the consensual coding strategy. The study identified the use of dominant stylistic devices such as repetition, parallelism, metaphor, personification and allusion in the sampled anthems. Repetition was used to emphasise the need for institutional solidarity. Parallelism was used to foreground the aims of the universities as well as create rhythmic effects to enhance the musicality in the anthems. Geographical and biblical allusions were used to establish religious and cultural hegemonies while personification and metaphor were also used to foreground the

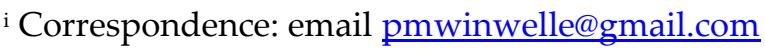


relevance and uniqueness of the institutions. The findings of the study have implications for research and practice. The study concludes that anthems of Ghanaian technical universities are not just construed as institutional symbols but also as mediums for marketing technical education.

Keywords: technical university anthems, stylistic devices, Technical and Vocational Educational Training (TVET), Ghana

\section{Introduction}

The inception of technical and vocational education in Ghana can be traced to the times of the Presbyterian Missionaries in 1844 where various crafts such as book binding, blacksmithing, carpentry, masonry, cookery, needle work and the likes were studied at the castle schools. It was until 1992 under the polytechnic law (PNDCL 321) that polytechnics were upgraded to tertiary status. Atakora and Yeboah (2012) proffer that it was in 1994 that polytechnics were allowed to offer Higher National Diplomas (HND). In 2013, the idea of converting polytechnics in Ghana into technical universities was conceived. Hitherto the conversion in 2016, there were ten polytechnics in Ghana with one evenly located in each of the ten traditional regions of Ghana. Currently, all ten polytechnics in Ghana have been converted into technical universities. Tertiary education in Ghana has been mainly focused on the acquisition of soft skills which alone denies a great number of students the chance of acquiring practical or hands on skills. This has increased the rate of unemployment where students complete school and are unable to create any employment for themselves unless they are employed by the government or other agencies. There have therefore been calls over the years for a type of education that caters for the development and enhancement of hard skills as well as make room for technical and vocational students who fail to enroll into the mainstream or traditional universities to acquire high-levelemployable skills. It is out of this need that technical and vocational education has been revamped in recent years to augment and cater for the lapses in mainstream traditional university educational system. Technical and vocational educational training is therefore geared towards the sciences and practically oriented courses in order to help students acquire a wide array of technical and vocational skills to make them employable in both formal and informal sectors.

As technical universities are made up of students and staff from diverse backgrounds, there is therefore the need to establish institutional symbols that would serve as cohesive ties to help build hegemony among members towards the accomplishment of the goals underlying the establishment of their institutions. Anthems usually align with the goals, aims and mission underpinning the establishment of institutions. For this reason, technical universities which were hitherto polytechnics have changed or altered their anthems to align with their new status as technical universities. Just like the traditional universities, technical universities also distinguish and represent themselves through symbols such as their logos, crests, other institutional paraphernalia and anthems (Mwinwelle, 2020). Atchoarena and Delluc (2001) establish that 
technical and vocational education in Ghana is not attractive enough which therefore makes it imperative that more publicity needs to be carried out to sensitize people to refrain from the erroneous notion that technical and vocational education is meant for the dull-minded. One of the potent means to enhancing the publicity of technical universities is through the use of powerful, attractive and appealing institutional symbols. Anthems of technical universities as institutional symbols therefore play a major role in making known their vision and mission in order to publicise and make them attractive to the general public. They may also indicate unique institutional identities and bond members of institutions. The present study therefore seeks to analyse the stylistic devices used in construing technical and vocational education in anthems of Ghanaian technical universities.

\subsection{Statement of Problem}

The relevance of technical and vocational educational training in development presents technical universities as very important institutions. The importance attached to technical universities latently is equally transferred to their anthems since anthems are institutional symbols. The lyrics and linguistic devices used in the composition of anthems of technical universities in Ghana are important data for linguistic research since they represent and reflect the main aims and goals underpinning the establishment of such institutions. It is in this light that the present study modestly contributes to literature on institutional anthems by seeking to examine the latent meanings encoded in the linguistic devices used in anthems of technical universities in Ghana. Discourse on anthems generally has attracted an appreciable amount of academic attention. There has been analysis of anthems in order to identify the latent meanings encoded in them. Most of the literature on anthems have focused on the analysis of national anthems from the perspective of Discourse and Stylistics Analysis such as (Souza, 2008; Bangura, 2011; Mwinlaaru, 2012; Dze-Ngwa, 2014; Azam and Negar, 2014; Mustafa, 2015; Oluga, Seng \& Rajoo, 2015a; Oluga, Send, Rajo, 2015b; Voros, et al. 2016; Onditi, 2018; Oyeyemi, 2018; Amenorvi and Grumah, 2019). Other studies examine institutional anthems such as university anthems (Mwinwelle, Adukpo and Mwinwelle, 2019; Mwinwelle, Amoakohene and Agyekum, 2020, Alabi, 2020 and Amenorvi, 2021) and football anthems (Krizan, 2016; Mwinwelle, Agbemehia and Mwinwelle, 2020). However, little is known about how technical universities employ various linguistic strategies in their anthems to drum home various ideas. Though there are studies that have looked at university anthems, they looked at only anthems of the traditional universities thereby relegating anthems of technical universities to the background, hence the need to examine and find out how technical universities also construe their identity and aims through their anthems. The paucity and the need for research on technical university anthems has been stressed (Mwinwelle, Adukpo and Mwinwelle, 2019; Mwinwelle, Amoakohene and Agyekum, 2020) in order to draw attention to the linguistic deficit in the analysis of anthems of technical universities and other unexplored institutional anthems. Anthems of technical universities unlike mainstream universities are geared toward trumpeting the goals of technical and vocational educational training. 


\subsection{Purpose of the Study}

The study seeks to examine the stylistic devices used in anthems of Ghanaian technical universities and the communicative functions encoded in such devices. The realization of these objectives will help establish how stylistic devices are used to market the goals of technical and vocational education training in anthems of Ghanaian technical universities.

\section{Literature Review}

Relative to the copious number of studies on national anthems (Souza, 2008; Bangura, 2011; Mwinlaaru, 2012; Dze-Ngwa, 2014; Azam and Negar, 2014; Mustafa, 2015; Oluga, Seng \& Rajoo, 2015a; Oluga, Send, Rajo, 2015b; Voros, Osvath, Vincze, Pusztay, Fekete \& Rihmer, 2016; Onditi, 2018; Oyeyemi, 2018; Amenorvi and Grumah, 2019), not much exist on institutional anthems. The few existing studies on institutional anthems have mainly focused on university anthems (Mwinwelle, Adukpo and Mwinwelle, 2019; Mwinwelle, Amoakohene and Agyekum, 2020, Alabi, 2020 and Amenorvi, 2021), and anthems of football clubs (Krizan, 2016; Mwinwelle, Agbemehia and Mwinwelle, 2020). The cardinal aim of this review is to examine works that have analysed the use of linguistic items in institutional anthems in order to indicate the place of the present study in the literature on the linguistic analysis of institutional anthems in general. The empirical review will help draw methodological and theoretical divergence and convergence as well as confirm and contest findings of earlier studies on institutional anthems.

\subsection{Review of Empirical Studies on the Linguistic Analysis of Institutional Anthems}

To begin with, one pioneering study on the linguistic analysis of institutional anthems is by Krizan (2016) who conducts an exploration of how linguistic resources are used in anthems of Slovenian and British football clubs to construe attitudes, form bonds and create identities. Nine anthems were used for the study which were made up of seven anthems of English football clubs and two anthems of Slovenian football clubs respectively. The study establishes that pronouns are dominantly repeated in the anthems to emphasise positive values such as supporters' commitment to the club, fandom and joint success, lexical items were used to construe values such as pride, hope, happiness and victory while colours, names of clubs and stadiums are used to indicate belongingness and familiarity.

To build on literature on the linguistic analysis of football anthems, Mwinwelle, Agbemehia and Mwinwelle (2020) examine how stylistic devices are used to project, construct and reflect various themes in the anthems of Real Madrid and FC Barcelona towards deepening the rivalry ties between them, theoretically underpinned by the linguistic and stylistic categories framework by Leech and Short (2007). The findings of the study generally indicate that stylistic resources such as repetition, co-referencing, metaphors, personification, and parallelism are used in the anthems to aesthetically project the themes of identity, solidarity, resilience and praises which further intensify the rivalry ties between the two clubs especially during El Clásicos (Matches between Real Madrid and FC Barcelona). 
Mwinwelle, Adukpo and Mwinwelle (2019) shift attention from football anthems to university anthems by exploring the use of lexical cohesive devices in selected Ghanaian university anthems underpinned by the lexical cohesion theory by Halliday and Hasan (1976). Their study identifies the predominant lexical cohesive devices and examines their communicative implications in the anthems of four selected Ghanaian Universities. Their study reveals that repetition was predominantly used to make the anthems lyrical and rhythmic in order to catch the attention of listeners while superordination was minimally used to economise the use of words in order to make the anthems less wordy thereby aiding easy memorisation.

As a sequel to Mwinwelle et al (2019), Mwinwelle, Amoakohene and Agyekum (2020) conduct a transitivity analysis of process types and their encoded communicative implications in selected Ghanaian university anthems underpinned by the transitivity framework by Halliday and Matthiessen (2014). The findings of the study indicate that among the process types used, material processes are preponderantly used to spell out the expected actions to be taken by members of the universities to contribute to the general progress of their institutions. The other process types such as relational, mental and verbal processes are used to present a plethora of communicative functions such as establish relationships, eulogize and personify the universities as important institutions worthy of praise.

Moreover, Mwinwelle (2020) conducts an analysis of the lyrics of the anthem of the University of Education, Winneba from the stylo-linguistic perspective underpinned by the linguistic and stylistic categories framework by Leech and Short (2007). The findings of the study reveal that simple lexical items are used aesthetically to boost the comprehension and memorization of the lyrics in the anthem; declarative and compound sentences as grammatical devices and figures of speech are used to express dignity and establish a strong correlation between the sound and lyrics in order to boost the musicality as well as highlight important ideas in the anthem whilst cohesive devices are used as linguistic adhesives to cement the ideas presented in the anthem.

Furthermore, Alabi (2020) employs the use of foregrounding by Mukařovský (1964) as a stylistic framework to examine the functions of phonological and lexical repetition, and graphological deviation in the anthems of five Nigerian universities. These anthems include Obafemi Awolowo University Anthem, University of Ilorin Anthem, Nigerian Defence Academy Anthem, University of Uyo Anthem and Federal University Lafia Anthem. The findings of the study reveal the use of lexical repetition, phonological repetition, punctuation and capitalisation to construe the universities as centres of knowledge and excellence. The results also indicate that staff and students love their universities and have a sense of pride in their great achievements or the potential to achieve great things. The study concludes that university anthems are thoughtfully and creatively crafted to reveal various communicative implications.

Last but not least, Amenorvi (2021) studies the emerging themes in anthems of six public universities in Ghana. His study purposively samples anthems of the three oldest and the three youngest public universities in Ghana namely University of Ghana, University of Cape Coast, University of Education, Winneba, University of Energy and Natural Resources, University of Health and Allied Sciences and University of Mines. The study generally identified three themes 
namely theme of self-importance, knowledge and religion which were projected through the use of lexical items and literary devices. Lexical items such as nouns, verbs, adjectives and adverbs were used while literary devices such as metaphor, hyperbole, pleonasm and personification were also used. The major difference identified between the old and young universities was that the old universities explicitly spelt out their self-importance while the young universities implicitly indicated their self-importance.

\subsection{Points of Convergence and Divergence between the Present Study and Previous Studies on Institutional Anthems}

Summarily, the review of empirical studies above has contributed significantly to establishing the relevance of the present study and also situate it appropriately in literature on the linguistic analysis of institutional anthems. From the empirical review above, it can be established that studies by Mwinwelle, Adukpo and Mwinwelle (2019), Mwinwelle, Amoakohene and Agyekum (2020), Mwinwelle (2020), Alabi (2020) and Amenorvi (2021) have a point of convergence in terms of the source of data. These studies all employ university anthems as their source of data which reveal interesting findings from varied theoretical perspectives. Another convergence in data source can be drawn between studies by Krizan (2016) and Mwinwelle, Agbemehia and Mwinwelle (2020) in that they both used football anthems as their data. Notwithstanding, they differ slightly on the premise that whereas Mwinwelle et al. (2020) focused on anthems of Spanish football clubs namely Real Madrid and FC Barcelona, Krizan's (2016) study was based on anthems of Slovenian and British football clubs. In terms of theoretical underpinnings, Mwinwelle, Agbemehia and Mwinwelle (2020), Mwinwelle (2020), Alabi (2020) and Amenorvi (2021) used the stylistic framework while the other studies employed quite diverse theoretical frameworks such as the transitivity framework (Mwinwelle, Amoakohene and Agyekum, 2020) and the theory of cohesion (Mwinwelle, Adukpo and Mwinwelle, 2019). From the methodological perspective, the present study together with all the studies reviewed use the qualitative descriptive methodology. Regarding theoretical framework, the present study just like studies by Mwinwelle, Agbemehia and Mwinwelle (2020) and Mwinwelle (2020) employ the linguistic stylistic categories framework by Leech and Short (2007).

In terms of findings, all previous studies on institutional anthems reviewed above unanimously identify institutional anthems as objects of internal solidarity and external competition thereby construing institutional anthems as bifunctional institutional symbols. Relating the studies reviewed to the present study, the current study can be said to be generally similar to all the studies reviewed because they all employ institutional anthems as their source of data but specifically similar to studies by Mwinwelle, Adukpo and Mwinwelle (2019), Mwinwelle, Amoakohene and Agyekum (2020), Mwinwelle (2020), Alabi (2020) and Amenorvi (2021) because they employed university anthems as their source of data. This study will seek to confirm or contest earlier findings on studies on institutional anthems in order to create solid basis for future studies to be carried out. The present study is therefore distinct from previous studies in this area as it aims at investigating the use of stylistic devices to market the goals of 
technical and vocational education in anthems of Ghanaian technical universities underpinned by the linguistic and stylistic categories framework (2007).

\section{Theoretical Framework}

The use of a theoretical framework in a study of this nature helps to tie the analysis of data to a particular theoretical perspective which lays a clear path for future researchers to evaluate and test the findings of the study. The analysis of language can be carried out from various theoretical perspectives. As such there exist a plethora of linguistic theories available to linguists for analysing linguistic data. Among the numerous theories available, the present study is theoretically framed by the linguistic and stylistic categories theory by Leech and Short (2007) because it serves a heuristic purpose which enables linguistic researchers to gather data on a fairly systematic basis. As a stylistically oriented framework, the linguistic and stylistic categories framework analyses "the use of language by a given person, in a given context for a given purpose" (Leech and Short, 2007, p. 9). Mwinwelle et al. (2020, p. 10) posit that 'Stylistic devices are the various linguistic devices used to project the style of a text or work.' These devices encode sufficient and justifiable communicative functions. The theory postulates that every text has peculiar features which make it different from others. It seeks to analyse how various texts employ stylistic devices in different ways to present their ideas. It serves as a useful checklist that guides linguists to analyse various aspects of language usage. The theory holistically stratifies stylistic devices into four main categories namely the lexical, grammatical, figures of speech, and cohesion and context categories. The lexical category explores the general use of lexical items, the grammatical category accounts for the syntactic components, the figures of speech category deals with linguistic foregrounded features while the context and cohesion category basically consider the ways in which the components of a text are connected and the circumstances surrounding the use of language.

Considering the holistic nature of the framework, researchers may only base their studies on specific aspects of the framework to achieve the specific goals of their studies. It is in this light that the current study is delimited to the third category in the framework, the figures of speech category. This category deals with foregrounded features in a text that have departed from the norms of communication by means of language code. Yankson (2011, p. 1) avers that "The language of literature and that of communal discourse share a common code. However, the literary discourse is characterised by deviations from the code". Linguists therefore consciously breach the language code in order to achieve linguistic foregrounding which enables them to highlight or forefront their intended message to attract the reader's attention. The use of figures of speech in a text therefore transmogrifies language use from literal to text non-literal (figurative). Mwinwelle (2020) establishes that figures of speech are words, phrases, sentences or writing devices which are used to create emphasis, concision, clarity, rhythm, novelty, peculiarity and style in order to ultimately achieve a rhetorical effect. The figures of speech category is organised into three sub-categories namely grammatical and lexical schemes, phonological schemes and tropes (Leech and Short, 2007). Grammatical and lexical schemes as a sub-category under the 
figures of speech category caters for the formal and structural repetitions in language such as anaphora and parallelism. It accounts for various paradigmatic relationships such as synonymous relationships, antonymous relationships, contextual conditioning, coupling and other relationships between repeated or similar linguistic structures. Phonological schemes drift from the structural patterning of language to look at the use of sound devices in a text and the underlying stylistic effect carried by these devices. Tropes are the last sub-category under the figures of speech category which are used to alter or change the meaning of sentences in different ways by the artistic use of words. This is done deliberately by misplacing words which is technically known as category rule violation. For instance, a particular word which is a verb can be consciously misplaced as a noun to indicate a specific stylistic effect. The figures of speech category subsumed under the general linguistic and stylistic categories framework is therefore used in identifying and analysing the stylistic devices used to project various goals of technical and vocational education training in anthems of Ghanaian technical universities.

\section{Methodology}

The study is a qualitative study which explored the use of literary devices to highlight the goals of technical and vocational education in anthems of Ghanaian technical universities. It was underpinned by the linguistic and stylistic categories framework postulated by Leech and Short (2007). The targeted population was made up of anthems of all ten (10) technical universities in Ghana which are strategically situated in the ten traditional regions in the country. This population was chosen by the researchers because anthems reflect the goals of the institutions they represent which therefore lays a premise to examine how these anthems encode the goals of technical and vocational education. Six (6) out of the ten (10) anthems were purposively sampled. The four anthems in the population that were eliminated from the sample were the anthems of Kumasi, Tamale, Bolga and Wa technical universities. Anthems of Kumasi and Bolga technical universities were excluded from the sample because they are not composed in English but in Twi and Gurene respectively while Tamale and Wa technical universities at the time of study had no anthems to reflect their status as technical universities. The six anthems that served as data for the study were anthems of Accra, Ho, Koforidua, Takoradi, Sunyani and Cape Coast Technical Universities. For the sake of identification, each of these anthems was coded using the abbreviation of the names of the institutions they represent. Accra Technical University was coded as ATU, Ho Technical University as HTU, Koforidua Technical University as KTU, Takoradi Technical University as TTU, Sunyani Technical University as STU and Cape Coast Technical University as CTU. The study employed the consensual manual code-recode strategy to code the data. To add a heuristic touch to the analytical procedure, the study adopted the fourfold textual analytical procedure postulated by Cohen (2007:470), namely: (1). "Generating natural unit of meaning", (2). "Classifying, categorizing and ordering these units of meaning", (3). "Structuring narratives to describe the contents of the text or speech", and (4). "Interpreting the data". In the generation of natural units of meaning, the lyrics of the selected anthems were parsed into lines. Secondly, the parsed lines were further classified and categorised into 
analysable units by being ordered from first to last in each of the anthems. The anthem of ATU was made up of fifteen (15) lines, HTU anthem twenty (20) lines, KTU anthem eight (8) lines, TTU anthem twelve (12) lines, STU anthem nine (9) lines and CTU anthem twelve (12) lines. To descriptively structure the content of the selected anthems, the lines in the anthems which contained literary devices were collectively used as illustrations to advance the discussion in the analysis of the data. Finally, the discussion of the structured data helped to establish context tied interpretations of the data.

\section{Results and Discussions}

The results of the analysis are discussed and structured based on the figures of speech category of the linguistic and stylistic categories framework postulated by Leech and Short (2007). First of all, the contextual use of stylistic devices in the figures of speech category of the framework are identified in the anthems. Secondly, the stylistic communicative functions underpinning the use of the devices identified are also discussed to establish how the use of these devices enhance the goals of technical and vocational education. Extracts are sourced from the anthems as illustrative materials to support the analysis and discussion of results.

\subsection{Repetition}

Repetition occurs as a stylistic device that carries a sound effect as it encodes some latent communicative functions. From the perspective of sound effects, repetition adds rhythmic effects to the lines in which they occur while their communication function is realized in the recurrence of linguistic structures to highlight what a writer seeks to present. The anthem employs repetition to create aesthetic effects. From the lines below, the repetitive use of the pronoun we is evident. Adetunji (2006) says that the pronoun we is mainly used to construe inclusion which includes the speaker and the audience. In sync with Adetunji's (2006) postulation, the pronoun we is used in the lines of the anthems of Ghanaian technical universities above to create a sense of institutional solidarity and bonding. Hamdaoui (2015) proffers that the use of the pronoun we has three different realizations: namely the universal we, the historical we, and the royal we. The universal we refers to the speaker and the audience, both the immediate audience and the implied audience, the historical we refers to the speaker and the audience as well as absent third persons either alive or dead while the royal we refers to the speaker and a group of partners. In the context of the repetition of we in the anthems, the royal we is used to spread the load of responsibility (Adetunji, 2006, p.183). In lines CTU 2,3,6,8 and 11, the pronoun we is used to construe the collective responsibility of members of Cape Coast Technical University in collectively standing for high quality, in training manpower, in upholding the culture and in brightening every corner. In lines ATU 6,9 and 11, the pronoun we is also used to reveal the collective responsibility of members of Accra Technical University in cherishing the institution, in learning and ultimately matching on to victory. In lines HTU 2,7, 15 and 17, the pronoun we is used to unite members of Ho Technical University to academic progress. Technical and vocational education unlike the traditional system of university education is underpinned by varied practical activities which 
require collective efforts to accomplish. The lines presented below are extracts from the anthems that contain the repetitive use of the first-person plural pronoun we.

- We stand for high quality career - oriented Programmes, CTU 2

We train manpower for industries; in Applied Sciences and Arts, CTU 3

We shall uphold our culture of high standards, CTU 6

We shall brighten every corner of the world. CTU 8

We shall brighten every corner of the world. CTU 11

- Well cherish, adore and love you in our heart. $A T U 6$

$W e^{\prime}$ re here to learn through Practice and Research. ATU 9

We'll match on to Victory ATU 11

- we have for you KTU 4

- We salute you, we hail your name// HTU 2

We resolve the hub Technological Education, $H T U 5$

... we shall strive to uplift thy name// HTU 7

We shall use our heart and hands for academically progressiveness. HTU 15

... we resolved to uphold thy name// HTU 17

Another form of repetition in the anthems is the repetition of names of various technical universities in their anthems. The repetition of names of institutions in their anthems may seek to create rhythmic effects and semantic implications in institutional anthems. In CTU1 and CTU9, Cape Coast Technical University is repeatedly personified as a deity that needs to be hailed, in ATU 5, ATU 7 and ATU 12, the name of the institution, Accra Technical University is stylistically abbreviated as ATU, in KTU 5 and KTU 8, the name of the university, Koforidua Technical University is repeated, in STU 1 and STU 2, the name of Sunyani Technical University is also repeated and finally, in HTU 1, HTU 8, HTU 11 and HTU 18 the name Ho Technical University is repeated as well. Semantically, the repetition of names of institutions serves as a symbol of identity in their anthems and the repetition of such names seeks to reinforce the identity of the said institutions. The repetition of the phrases Cape Coast Technical University and Takoradi Technical University create some alliterative effects with the repetition of the $/ \mathrm{k} / \mathrm{and} / \mathrm{t} /$ sounds. The repeated names of the universities are strategically positioned at the beginning, in the middle and in the last lines in the anthems. This strategic repetition of the names of the universities at the beginning, in the middle and in the last lines of their respective anthems seeks to ingrain the names of the universities in the minds of their members during and after singing these anthems. (Mwinwelle, et al. 2020). Aside being a symbol of identity, repetition of names of technical universities in their anthems also seeks to enhance the musicality in the singing of the anthems since these repetitions enrich the rhythmic effects in the anthems. The lines presented below are 
illustrations from the anthems that contain the repetitive use of the names of technical universities who own these anthems.

- Hail Cape Coast Technical University, CTU 1

O Hail Cape Coast Technical University, CTU 9

- Floreat, Floreat ATU forever more ATU 5

Arise, $\mathrm{Oh} A T U$, Arise and Shine, ATU forever more. ATU 7

All hail $A T U$, my Alma mater. ATU 12

- Arise for K'dua Technical University KTU 1

for koforidua Technical University through University. KTU 8

- Great Takoradi Technical University TTU 9

- Sunyani Technical University, Centre of excellence! STU 1

Sunyani Technical University: they that learn discover. STU 9

- Ho Technical University, we adore you HTU 1

All hail, Ho Technical University, all hail our alma mater, HTU 8

// Ho Technical University on Asogli Land HTU 11

arise Ho Technical University, arise, arise our alma mater HTU 18

\subsection{Parallelism}

Parallelism happens to be one of the linguistic devices used in the anthems to establish a strong bond amongst linguistic items or structures used. Various parallel structures in the form of words, phrases and sentences are used to signal some form of sound and semantic implications. The parallel structures in CTU 6 and CTU 8 are made up of the structure SVO. The subjects and objects are both noun phrases linked by the verb phrases shall brighten and shall uphold. There is a repetition of the subjects We which seeks to reinforce the reference to members of the university. The verb phrase shall brighten and shall uphold are in a paradigmatic relationship where the verbs brighten and uphold are contextually invested with phonological similarity ie they are both disyllabic words which translates into a semantic similarity. The objects our culture of high standards and every corner of the world are in a paradigmatic relationship because they are all noun phrases with the structure (Det + Noun + of +Adj/Det. + Noun). The similarity in the grammatical structure of the objects translate into a semantic similarity thereby intra-textually conditioning the head nouns in the objects Standards and World as synonyms where the world is influenced by standards and standards can also determine the state of the world.

In HTU 7 and HTU 17 the parallel structures, in thick or thin, in rain or shine and in joy or in grief, by day or night are used to construe various seasons, times, conditions and moods which stylistically unveil the strong united and unconditional commitment on the part of members of 
the university to ensure the progress of their institution. In CTU 3 and CTU 4, parallelism is used as a stylistic device to the areas of study at Cape Coast Technical University. These areas of study are captured in the form of noun phrases Such as Applied Sciences and Arts, Vocational and Technical Education and Research for national and global development.

In ATU 10, the parallel structure is made up of the words Head, Heart and Hand which are all monosyllabic singular nouns that begin with the consonant $/ \mathrm{h} /$ which creates an alliterative effect. These phonological similarities in the words therefore translate into a semantic similarity where all the words are contextually assigned the same meaning and importance. These words are stylistically used to construe the holistic form of education given by the University where the head represents the intellect, the heart represents emotion and the hand represents hard skills. The institution prioritises all these three forms of education. Products of the university are therefore trained academically, emotional and vocationally.

Other parallel structures are used in CTU 7, ATU 3 and STU 6 to associate various positive qualities to the universities. For instance, in STU 6 positive qualities such as Excellence, Competence, Competitiveness Responsiveness are used to define Sunyani Technical University. The use of these qualities creates some form of balanced rhythmic effect where the words Excellence and Competence have a similar end rhyme while the words Competitiveness and Responsiveness also have a similar end rhyme. This is stylistically arranged to enhance the musicality of the words in the anthem. The lines below were used to advance the discussions on parallelism in the anthems.

- We shall uphold our culture of high standards, CTU 6

We shall brighten every corner of the world. CTU 8

With Dedication, hard work and Perseverance, $C T U 7$

We train manpower for industries; in Applied Sciences and Arts, CTU 3

Vocational and Technical Education and Research for national and global development. CTU 4

- Integrity, Creativity, Excellence $A T U 3$

With Head, Heart and Hand,...ATU 10

- Excellence, Competence, Competitiveness Responsiveness. STU 6

- //: in thick or thin, in rain or shine, we shall strive to uplift thy name// HTU 7

// in joy or in grief, by day or night, we resolved to uphold thy name// HTU 17

\subsection{Allusions}

Allusions refer to the references made to various historical events or entities. They could be related to religion, geographical locations and general historical events. Geographical allusions are dominantly used to indicate the location as well as the specific areas covered by these institutions. In HTU 11 and ATU 12, the location of Ho Technical University is indicated through the use of the Asogli Land, Kodzobi Land and Volta soil. These locations identify the university 
as located in the Volta Region of Ghana and specifically on the Asogli and Kodzobi lands. In ATU 8, the locations, Kinbu and Mpehuasem refer to the areas where campuses of Accra Technical University can be located. These locations therefore define the boundaries of the institution since it is located in the busiest as well as the capital city of the nation, Ghana. Religious allusions are also used in TTU 8, HTU 16 and HTU 20 to identify God as a supernatural force who can help the institutions to succeed as confirmed by Mwinwelle et al (2020. P. 22) "God is therefore considered as the mighty one who has the power to help the university progress and develop." The lines below were used to advance the discussions on allusions in the anthems.

- // Ho Technical University on Asogli Land HTU 11

Kodzobi land, on Volta soil// HTU 12

- From Kinbu to Mpehuasem, $A T U 8$

In God we trust TTU 8

Forever and ever, God be our help. HTU 16

God bless thee/ HTU 20

\subsection{Metaphors}

A metaphor is a linguistic device which is used to directly compare one entity to another. The anthems contain a number of metaphors hinged on the universities as the source domains and other entities as the target domains. In ATU 2 and ATU 13, Accra Technical University is referred to as Home of Technical and Vocational Skills and Lustrous City of Technocrats. In the metaphors, the source domain is ATU while the target domains are home and city. The university is compared to a home to indicate that it is a welcoming place and compared to a city to show that it is a place of development. The use of these metaphorical attributes also helps in identifying the mandate of the university as one that seeks to promote vocational, technical and technological education. In STU 1, the Sunyani Technical University (source domain) is compared to a Centre of excellence (target domain) while in HTU 3 and 13, Ho Technical University (source domain) is construed as a gate of Knowledge and the Star of Volta (target domain). Metaphors are used in the anthems to construe the universities as educational institutions that seek to present the best of technical and vocational education. The lines presented below are extracts from the anthems used to back the discussion above.

- Accra Technical University ATU 1

Home of Technical and Vocational Skills. ATU 2

Lustrous City of Technocrats. ATU 13

- Sunyani Technical University, Centre of excellence! STU 1

- ......the gate of knowledge HTU 3

.........the star of Volta HTU 13 


\subsection{Personification}

Personification is used as a stylistic device to construe the universities as animate entities that carry out some actions and need to be loved and cherished by their members. Words such as Hail, arise, adore, salute, you, thou and thee are used to present technical universities as worthy animate entities that deserve to be revered. For instance, in the lines CTU 1, CTU 2, ATU 12, HTU 1 and HTU 2 as presented below, the verbs hail, adore and salute are used to personify the universities as animate entities that deserve to be revered, eulogised, honoured and dignified as sacred entities worthy to be adored (Grancea and Blaga, 2013; Mwinwelle, 2020). Again, the word arise is used in line ATU 7 to refer to the institution as an animate active entity that has the potency to carry out physical actions. Finally, thee, thou and you in lines ATU 6, ATU 14, KTU 3, HTU 1, HTU 2, HTU 3, HTU 10 and HTU 13 are used in order to avoid the unnecessary repetition of the names of the universities. The use of the pronoun you and its variants (thee and thou) usually refer to the person(s) spoken to by the speaker (Mwinwelle, Adukpo and Mortey, 2019). The use of these pronouns therefore foregrounds the universities as human beings who are cherished and loved as well as need the blessing of God to make progress. This subtly invites the university to grow and make progress as human beings do. The lines below illustrate the discussions on the use of personification in the anthems.

- Hail Cape Coast Technical University, CTU 1

O Hail Cape Coast Technical University, CTU 9

- We'll cherish, adore and love you in our heart. ATU 6

Arise, Oh ATU, Arise and Shine, ATU forever more. ATU 7

All hail ATU, my Alma mater. ATU 12

Be thou our Strength in the World of Work, ATU 14

- Great is the love we have for you KTU 3 and 4

- Ho Technical University, we adore you HTU 1

We salute you, we hail your name// HTU 2

All hail, Ho Technical University, all hail our alma mater, HTU 8

You have opened unto us, ... HTU 3

God bless thee. // HTU 10

You have championed our course, ... HTU 13

\section{Summary of Findings and Conclusions}

From the discussion and analysis of findings regarding the use of stylistic devices in anthems of Ghanaian technical universities, the study identified the use of stylistic devices such as repetition, parallelism, metaphor, personification and allusion in the anthems. Repetition of the plural first person pronoun we and the names of the various technical universities were predominantly 
repeated in order to stress the need for institutional solidarity and identity. The analysis of parallelism catered for various phonological devices such as alliteration, assonance, rhyme and syllabification. Parallelism was used to foreground various ideas (The courses offered, the holistic form of educational training, the unconditional commitment of members and the attribution of various positive qualities to the universities) and create rhythmic effects to enhance the musicality in lyrics of the anthems. Geographical allusions were mainly used to indicate the location of the institutions while religious allusions are used to identify God as a supernatural force who has the power to help the institutions achieve their goals. Metaphors were used to positively construe the universities as unique educational institutions that seek to offer the best of technical and vocational education while personifications were used to foreground the universities as human beings who need to be cherished and adored.

A plethora of conclusions are drawn from the study. First and foremost, the study concludes that Ghanaian technical university anthems serve as icons of institutional solidarity and identity in that they seek to unite their members and also create unique identities for respective technical universities. In addition, they are used to self-project the image of their institutions in order to market the goals of technical education. As a marketisation principle, they further construe technical education as a holistic form of education which therefore places products of technical universities better than their counterparts from the traditional universities. Also, anthems of technical universities are used as an altar of praise to adore and eulogise their institutions. Finally, they are used to establish religious hegemony by identifying God as their ultimate source of help.

\subsection{Implications for Research and Practice}

In terms of research, findings drawn from the study will serve as a good reference material for language students and teachers who wish to study about institutional anthems. Other linguistic researchers in other parts of the world or continents may find this work useful in that it will help them conduct similar analysis on anthems of their universities to examine how culture plays out in the composition of institutional anthems. In relation to practice, it will help Ghanaian technical universities evaluate the lyrics of their anthems to see if the lyrics actually represent the goals of their institutions. Anthems of Ghanaian technical universities must not just be construed as institutional symbols but also an avenue for marketing the goals of the institutions. The study confirms that anthems are powerful poetic pieces that contain inexhaustible meanings encoded in few words (Oyeyemi, 2018; Mwinwelle, 2020). The study strongly recommends that anthems of Ghanaian educational institutions should be composed in English and if possible, with versions in other Ghanaian languages in order to market the goals of educational institutions locally and internationally.

\subsection{Recommendations for Further Research}

The present study is a modest contribution to literature on institutional anthems generally and a novel contribution to the linguistic analysis of anthems of technical universities by seeking to identify how technical universities employ stylistic devices to encode the goals of technical and 
vocational educational training in their anthems. Future studies could consider working on the analysis of semantic sense relations in institutional anthems in order to find out the dominant sense relations and their semantic implications. Findings of such a study will help composers of institutional anthems select their words carefully in order not to misrepresent what they seek to put across. Anthems of other educational institutions either than universities could also be analysed from various linguistic perspectives in order to confirm or contest previous findings on the analysis of university anthems and also ascertain the similarities and differences between university anthems and anthems of other educational institutions.

\section{Conflict of Interest Statement}

The authors declare no conflicts of interests.

\section{About the Authors}

Peter Mwinwelle is an Assistant Lecturer in the Department of General Studies, Koforidua Technical University, Ghana and a PhD Candidate in English Language at the University of Ghana, Legon (UG). His research interests include Systemic Functional Grammar, Discourse Analysis, Stylistic Analysis, Literary Studies, and Biblical Linguistic Studies.

John Adupko is an English Language Tutor in the Department of Languages, Dambai College of Education, Ghana and a PhD Candidate in English Language at the University of South Africa (UNISA). His research interests include Systemic Functional Grammar, Sociolinguistics and Stylistic Analysis.

Grace Asante-Anyimadu is an English Language Tutor in the Department of Languages, Methodist College of Education, Akim Oda, Ghana. Her research interests include Systemic Functional Grammar, Discourse Analysis and Stylistic Analysis.

Anita Avevor is an English Language Tutor in the Department of Languages, Dambai College of Education, Ghana. Her research interests include Systemic Functional Grammar, Sociolinguistics, Religious Discourse Analysis and Stylistic Analysis.

\section{References}

Adetunji, A. (2006). Inclusion and exclusion in political discourse: Deixis in Olusegun Obasanjo's speeches. Journal of Language and Linguistics 5(2), 177-191.

Alabi, V.T. (2020). A stylistic analysis of the anthems of five Nigerian universities. Marang: Journal of Language and Literature. Vol. 33, pp. 152-166.

Amenorvi, C.R. (2021). A thematic analysis of anthems of Ghana's public universities: A case of six. Research Journal in Advanced Humanities. 2(2). Retrieved from https://royalliteglobal.com/advanced-humanities/article/view/246.

Amenorvi, C.R. and Grumah, Y.G. (2019). A thematic analysis of the national anthems of English West Africa. The Journal of Applied Linguistics and Applied Literature: Dynamics and Advances. Vol. 7(1), pp. 141-151. 
Atakora, A., \& Yeboah, A. (2012). Achieving Quality Assurance of Polytechnic Education in Ghana: The Role of Stakeholders. International Journal of Innovative Research and Development, 1(8), 428-447.

Atchoarena, D. \& A. Delluc (2001). Revisiting Technical and Vocational Education in SubSaharan Africa: An Update on Trends, Innovations and Challenges. Paris: International Institute for Educational Planning, World Bank.

Azam, S. and Negar, D.A. (2014). Exploring linguistic structure and content of national anthems: a comparative study of Asian countries and the five permanent members of UN Security Council. Journal of literary Criticism. Vol. 7(26) pp. 91-122.

Cohen, L. (2007). Research Methods in Education. London: Routledge.

De Souza, A.A. (2008). The construal of interpersonal meanings in the discourse of national anthems: An appraisal analysis. Proceedings 33rd International Systemic Functional Congress, 531-550.

Dze-Ngwa, W. (2014). Rethinking Cameroon's national anthem and the challenges to internal cohesion: A historical review, fifty years after independence and reunification. International Journal of Liberal Arts and Social Science. 2(7), 91-101.

Grancea, M. and Blaga, L. (2013). The anthem, a component of nationalism as a religion of suffering. Unpublished paper at the Universitatii, Petru Maior.

Hamdaoui, M. (2015). The Persuasive Power of Person Deixis in Political Discourse: The Pronoun "We" in Obama's Speeches about the 2007-2009 Financial Crises as an Example. European Conference on Arts \& Humanities, Official Conference Proceedings (pp. 99111). Thistle Brighton, Brighton, United Kingdom, 13-16 July.

Križan, A. (2015). The language in British and Slovene football anthems. ELOPE. Vol. 13 (1), pp. 15-29 doi:10.4312/ elope.13.1.15-29.

Leech, G. \& Short, M. (2007). Style in fiction: A linguistic introduction to English fictional prose (2nd ed). Great Britain: Pearson Education Ltd.

Mustafa, E. (2015). Semantic framing of nationalism in the national anthems of Egypt and England: A cognitive study. Linguistics and Literature Studies. 3(5), 179-193.

Mwinlaaru, I. N. (2012). Metafunctional profile and the rhetoric of national anthems of Anglophone Africa: A preliminary exploration. Paper presented at the 9th InterUniversity Conference on the Co-existence of Languages in West Africa, November 12.

Mwinwelle, P. \& Adukpo, J. (2019). A lexical stylistic analysis of Kwame Nkrumah's 1957 Independence Day Declaration Speech. International Journal of Art, Language E Linguistics. Vol. 1 (2), 85 - 96 retrieved on 26th July, 2019 from https://zambrut.com/food-inflation/

Mwinwelle, P. (2020). Institutional Symbolism and Solidarity: A Stylo-linguistic exploration of the anthem of the University of Education, Winneba. International Journal of Art, Language $\mathcal{E}$ Linguistics. Vol. 2 (2), 15 - 33 retrieved on 22nd May, 2020 from https://zambrut.com/linguistic-exploration/

Mwinwelle, P., Adukpo, J. \& Mwinwelle, R. (2019). The Use of Lexical Cohesive Devices in Selected Ghanaian University Anthems. International Journal of Social, Politics $\mathcal{E}$ 
Humanities. Vol. 4 (2), 161 - 172 retrieved on 26th July, 2019 from https://zambrut.com/lexical-cohesive/

Mwinwelle, P., Agbemehia, K. G. and Mwinwelle, R. (2020). A stylo-thematic analysis of rivalry in football anthems of Real Madrid and FC Barcelona. Advances in Language and Literary Studies, 11(2), 8-15. http://dx.doi.org/10.7575/aiac.alls.v.11n.2-p.8

Mwinwelle, P., Amoakohene, B. and Agyekum, O. N. (2020). Creating institutional solidarity: A transitivity analysis of anthems of selected Ghanaian Universities. Advances in Language and Literary Studies. 11(2), 74-83. http://dx.doi.org/10.7575/aiac.alls.v.11n.2-p.74

Oluga, S. M., Send, T. C., Rajo, G.S.R. (2015a). Manipulative figurative linguistic violence of contemporary national anthems: A socio-cognitive critical discourse analysis. International Journal of Humanities and Social Sciences. 2(12), 9-20.

Oluga, S. M., Seng, T.C. \& Rajoo, G.S.R. (2015b). The paradox of the quest for global peace and the linguistic violence of some countries' national anthems: A critical discourse perspective. Global Journal of Human-Social Science: Linguistics and Education. 15(1), 82-85.

Onditi, F. (2018). African national anthems: Their value system and normative 'potential'. African Study Monographs, Suppl. 56: 3-20, March.

Oyeyemi, A.S. (2018). The Nigeria's national anthem: A text linguistic exploration. International Journal of English Language and Linguistics Research. Vol. 6(1), pp. 31-38.

Voros,V., Osvath, P., Vincze, O., Pusztay, K., Fekete, S. \& Rihmer, Z. (2016). Word use and content analysis of the first verses of six national anthems: A transcultural aspect of suicidal behaviour. Psychiatria Danubina. 28(1), 82-85.

Wang, B. and Ma, Y. (2018). Choices in recreating the anthem of the PRC in English: A systemic functional analysis. Proceedings of the Seventh Northeast Asia International Symposium on Language, Literature and Translation: The American Scholars Press, Pp. 27-32. 


\section{Appendix}

\section{Anthem of Sunyani Technical University (STU)}

Sunyani Technical University, Centre of excellence! STU 1

Training high level manpower for development. STU 2

Career focused education with hands-on experience STU 3

Sunyani Technical University. STU 4

They that learn discover. STU 5

Excellence, Competence, Competitiveness Responsiveness. STU 6

In our service to the Nation, we apply professionalism. STU 7

Entrepreneurial development to fit where ever we are. STU 8

Sunyani Technical University: they that learn discover. STU 9

\section{Anthem of Takoradi Technical University (TTU)}

Our Hallmark is quality and excellence, TTU 1

In vocational, technical, applied sciences and arts $T T U 2$

Our unique training in human resources. TTU 3

\section{Refrain:}

ADWEN AKOMA NA NSA MA MPUNTU TTU 4

We Stand for EXELLENCE where ever we are TTU 5

We are the best among them all. TTU 6

The sky is our limit in God we trust TTU 7

In God we trust TTU 8

Great Takoradi Technical University TTU 9

We are known for DISCIPLINE and DELIGENCE TTU 10

We are CAPABLE, COMPETENT in all we teach and learn TTU 11

To develop SKILLED man power for our nation. TTU 12

\section{Anthem of Ho Technical University (HTU)}

//: Ho Technical University, we adore you HTU 1

We salute you, we hail your name// HTU 2

You have opened unto us, the gate of knowledge HTU 3

To develop our skills to perfection $H T U 4$

We resolve the hub Technological Education, HTU 5

In Ghana, Africa and beyond. HTU 6

//: in thick or thin, in rain or shine, we shall strive to uplift thy name// HTU 7

//: All hail, Ho Technical University, all hail our alma mater, HTU 8

All hail the stars and primus inter pares of all time, HTU 9

God bless thee. // HTU 10

// Ho Technical University on Asogli Land HTU 11

Kodzobi land, on Volta soil// HTU 12 
You have championed our course, the star of Volta HTU 13

To keep burning our touch for human kind. HTU 14

We shall use our heart and hands for academically progressiveness. HTU 15

Forever and ever, God be our help. HTU 16

// in joy or in grief, by day or night, we resolved to uphold thy name// HTU 17

// arise Ho Technical University, arise, arise our alma mater HTU 18

Arise the star and primus inter pares of all time, HTU 19

God bless thee/ HTU 20

Anthem of Koforidua Technical University (KTU)

Arise for K'dua Technical University KTU 1

Your worth no tongue can tell KTU 2

Great is the love KTU 3

we have for you KTU 4

to attain greater height $K T U 5$

through industry information technology and Engineering and Knowledge KTU 6

that blessing and peace may descend on Ghanaian development and stability KTU 7

for Koforidua Technical University through university. KTU 8

\section{Anthem of Accra Technical University (ATU)}

Accra Technical University ATU 1

Home of Technical and Vocational Skills. ATU 2

Integrity, Creativity, Excellence ATU 3

Is our motto. ATU 4

\section{Refrain}

Floreat, Floreat ATU forever more ATU 5

well cherish, adore and love you in our heart. ATU 6

Arise, Oh ATU, Arise and Shine, ATU forever more. ATU 7

Verse 2

From Kinbu to Mpehuasem, ATU 8

We're here to learn through Practice and Research. ATU 9

With Head, Heart and Hand, Truth and Diligence. ATU 10

We'll match on to Victory ATU 11

\section{Verse 3}

All hail ATU, my Alma mater. ATU 12

Lustrous City of Technocrats. ATU 13

Be thou our Strength in the World of Work, ATU 14

Forever and Evermore ATU 15

Anthem of Cape Coast Technical University (CTU)

Hail Cape Coast Technical University, CTU 1 
We stand for high quality career - oriented Programmes, CTU 2

We train manpower for industries; in Applied Sciences and Arts, CTU 3

Vocational and Technical Education and Research for national and global development. CTU 4 "Nkyerekyere Na Nyimdzee Ma Nyansa" CTU 5

We shall uphold our culture of high standards, CTU 6

With Dedication, hard work and Perseverance, $C T U 7$

We shall brighten every corner of the world. CTU 8

O Hail Cape Coast Technical University, CTU 9

Arise for your Nation's call, CTU 10

We shall brighten every corner of the world CTU 11

forever more. CTU 12 
Peter Mwinwelle, John Adukpo, Grace Asante-Anyimadu, Anita Avevor

MARKETISATION OF TECHNICAL EDUCATION: A STYLISTIC

EXPLORATION OF GHANAIAN TECHNICAL UNIVERSITY ANTHEMS

Creative Commons licensing terms

Author(s) will retain the copyright of their published articles agreeing that Creative Commons Attribution 4.0 International License (CC BY 4.0) terms will be applied to their work. Under the terms of this license, no permission is required from the author(s) or publisher for members of the community to copy, distribute, transmit or adapt the article content, providing a proper, prominent and unambiguous attribution to the authors in a manner that makes clear that the materials are being reused under permission of a Creative Commons License. Views, opinions, and conclusions expressed in this research article are views, opinions, and conclusions of the author(s). and European Journal of Literature, Language and Linguistics Studies shall not be responsible or answerable for any loss, damage, or liability caused in relation to/arising out of conflicts of interest, copyright violations, and inappropriate or inaccurate use of any kind of content related or integrated into the research work. All the published works are meeting the Open Access Publishing requirements and can be freely accessed, shared, modified, distributed, and used for educational, commercial, and non-commercial purposes under a Creative Commons Attribution 4.0 International License (CC BY 4.0). 